$\begin{array}{cc}\text { ACADEMIA ROMÂNĂ } & \text { Rev. Roum. Chim., } \\ \text { 2019, 64(10), 915-921 }\end{array}$

\title{
COMPARATIVE CHEMICAL MODIFICATION OF STARCHES AS A FUNCTION OF THEIR ORIGIN: SYNTHESIS AND ANALYSIS
}

\author{
Diana Felicia LOGHIN, ${ }^{*}$ Ecaterina Stela DRĂGAN and Marcela MIHAI \\ “Petru Poni” Institute of Macromolecular Chemistry, 41A Grigore Ghica Vodă Alley, 700487 Iaşi, Roumania
}

Received October 26, 2018

\begin{abstract}
The paper follows the chemical modification of different sorts of starch after grafting and hydrolysis reactions. The grafting reaction of acrylonitrile on the starches from potato, wheat and rice, took place using $\mathrm{Ce}\left(\mathrm{SO}_{4}\right)_{2}$ in $\mathrm{H}_{2} \mathrm{SO}_{4} 0.4 \mathrm{M}$, as initiator system. Even if the grafting reaction with this initiator system has been already discussed in the literature, this paper aims a comparison of the product characteristics as a function of starch source. The synthesis of water soluble polymers was performed by the basic hydrolysis of the grafted starches. The grafted and hydrolyzed copolymers were characterized by FT-IR and ${ }^{1} \mathrm{H}-\mathrm{NMR}$ spectroscopy, scanning electron microscopy (SEM) and energy dispersive X-ray analysis (EDAX).

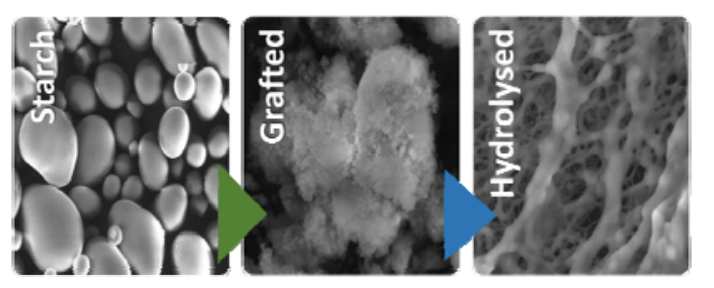

\section{INTRODUCTION}

Polysaccharides are the most abundant renewable resource on earth, with an annual rate exceeding world production of synthetic polymers, ${ }^{1,2}$ showing specific properties, such as: biocompatibility, biodegradability, polyfunctionality, high chemical reactivity, sorption capacity and chelating of different ionic species. The sorption capacity of polysaccharides is ascribed to the high hydrophilicity, due to the presence of hydroxyl groups from the glycoside units, and to the presence of a large number of functional groups (acetamide, primary amine, hydroxyl) with high chemical reactivity. Chemical modification of polysaccharides, in particular crosslinking and grafting, can lead to interesting macromolecular suprastructures, such as gels, hydrogels, polymeric resins, beads, membranes, fibers, composites, offering many opportunities for different applications. ${ }^{3-5}$

Starch is the most important ingredient in food with a long history in various applications and can be 
properties (biodegradation, thermal stability and metal ion-binding capacity) and their use in various industrial applications. ${ }^{12,13}$ The graft copolymerization reaction of vinyl monomers onto starch in the presence of $\mathrm{Ce}^{4+}$ ions is already known as one of the most convenient ways to change the properties of starch. ${ }^{14-17}$ In particular, the grafting of acrylonitrile (AN) on starch offers the possibility of carrying out further chemical reactions and to synthesize new materials with properties suitable for various applications such as: reconditioning soil, additives for paper and textiles, adhesives, sanitary systems for controlled release of drugs, wastewater remediation, etc. ${ }^{18-21}$

In this context, the aim of this paper was to follow the structure modifications after grafting and hydrolysis of different sorts of starch. Therefore, the grafting reaction of AN on the starch from potato (PSt), wheat (WSt) and rice (RSt) has been followed, using as initiator $\mathrm{Ce}\left(\mathrm{SO}_{4}\right)_{2}$ in $\mathrm{H}_{2} \mathrm{SO}_{4} 0.4$ $\mathrm{M}$. Even if the grafting reaction with the same initiator systems has been already discussed in literature, this paper aims a comparison of the product characteristics as a function of starch source. In the second part, the synthesis of water soluble polymers was studied following the hydrolysis of the grafted starches. The grafted and hydrolyzed copolymers were characterized by FTIR and ${ }^{1} \mathrm{H}-\mathrm{NMR}$ spectroscopy, scanning electron microscopy (SEM) and energy dispersive X-ray analysis (EDAX).

\section{RESULTS AND DISCUSSION}

The size and shape of starch granules depend on the botanical origin, Fig. 1 showing the granular morphology of PSt, WSt and RSt samples, respectively. Thus, PSt exhibits the largest and asymmetrical granules, the deviation of the sphericity being clearly shown by the elongated forms. Polydispersity is a common feature of all types of starch and WSt shows the highest one, a large number of small grains along with many large grains being evident, while intermediate sizes are apparently missing. Most of the WSt granules appear to be spherical, although some of the larger granules could be slightly flattened, corresponding to the lenticular forms described in the literature. Rice starch presents the smallest size of all, having an isometric form, often non-spherical (polyhedral). ${ }^{22}$

The starch based graft copolymers are prepared by chemical initiation, free radicals being generated in the starch backbone as fixing centers for synthetic homopolymers. In this work, the initiator system for grafting reaction of $\mathrm{AN}$ on the starch from different sources was $\mathrm{Ce}\left(\mathrm{SO}_{4}\right)_{2}$ in $\mathrm{H}_{2} \mathrm{SO}_{4}$ 0.4 M. Therefore, the initiation mechanism involves the formation of a complex between $\mathrm{Ce}^{4+}$ ions and $-\mathrm{OH}$ groups of the starch located at the carbon atoms in the positions $\mathrm{C}_{2}$ and $\mathrm{C}_{3}$, opening the AGU units and generating free radicals. The grafting of AN occurs at the active centers of the starch, $\mathrm{Ce}^{4+}$ ions being reduced to $\mathrm{Ce}^{3+}$, as previously described. ${ }^{17,23}$

Table 1

Characteristics of starch depending on the botanical sources

\begin{tabular}{|c|c|c|c|c|}
\hline Botanical source & $\begin{array}{c}\text { Amylose } \\
(\%)\end{array}$ & $\begin{array}{c}\text { Amylopectin } \\
(\%)\end{array}$ & Rate of swelling & Physical properties \\
\hline Rice & $17-30$ & $70-83$ & Slower & Opac solution \\
\hline Potato & $20-21$ & $79-80$ & Fast & Clear solution \\
\hline Wheat & $25-30$ & $70-75$ & Slower & Opac solution \\
\hline Corn & $25-28$ & $72-75$ & Slower & Opac solution \\
\hline Tapioca & $16-17$ & $83-84$ & Slower & Clear solution \\
\hline
\end{tabular}

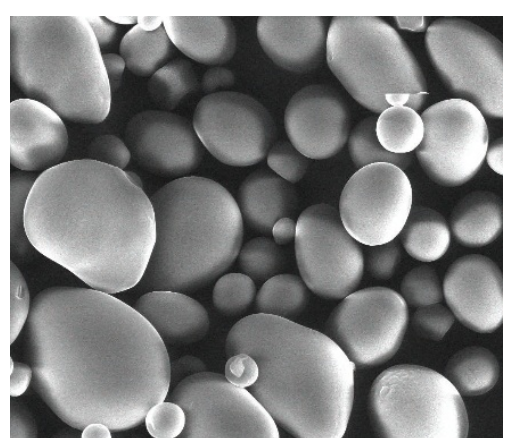

PSt

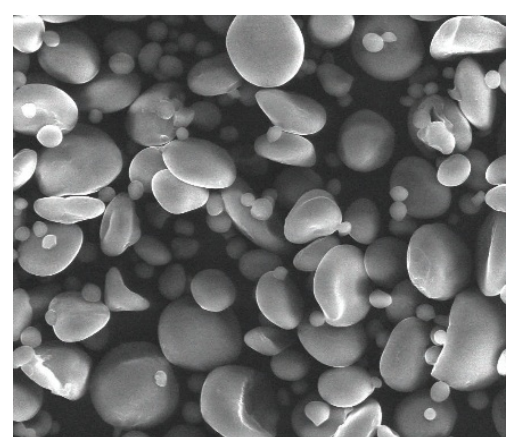

WSt

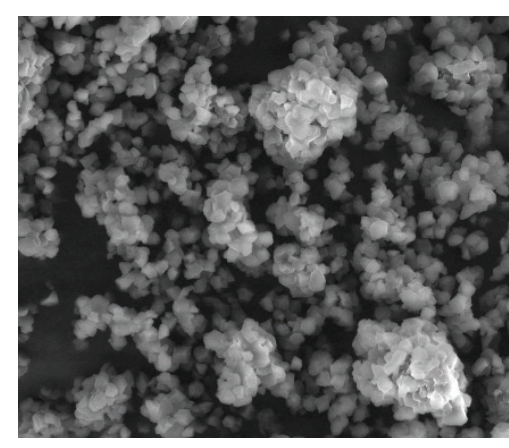

RSt

Fig. 1 - SEM micrographs of starch from potato (PSt), wheat (WSt) and rice (RSt); scale bar $-50 \mu \mathrm{m}$. 


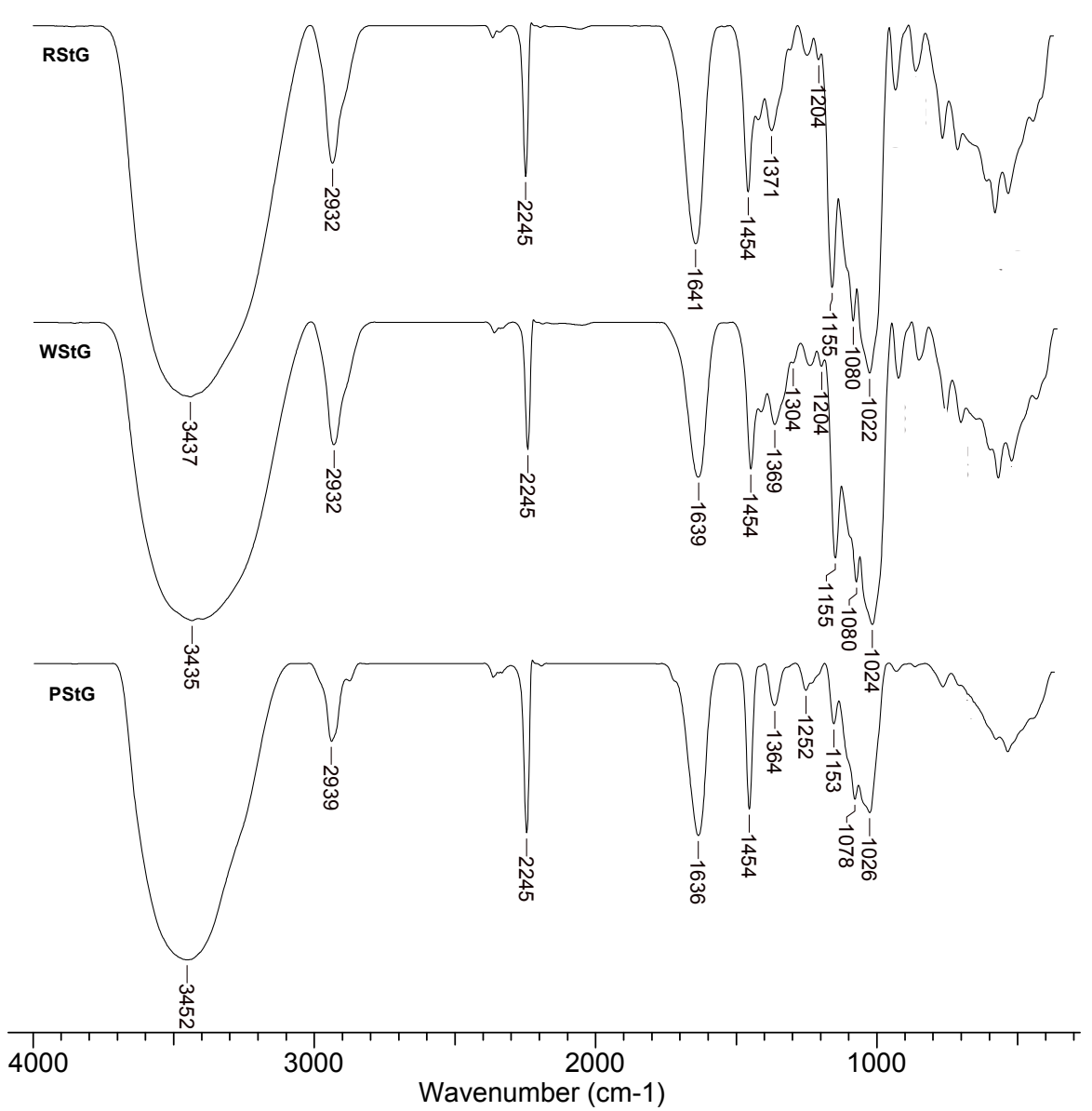

Fig. 2 - FT-IR spectra of the grafted acrylonitrile on starch from potato (PStG), wheat (WStG) and rice (RStG) compounds.

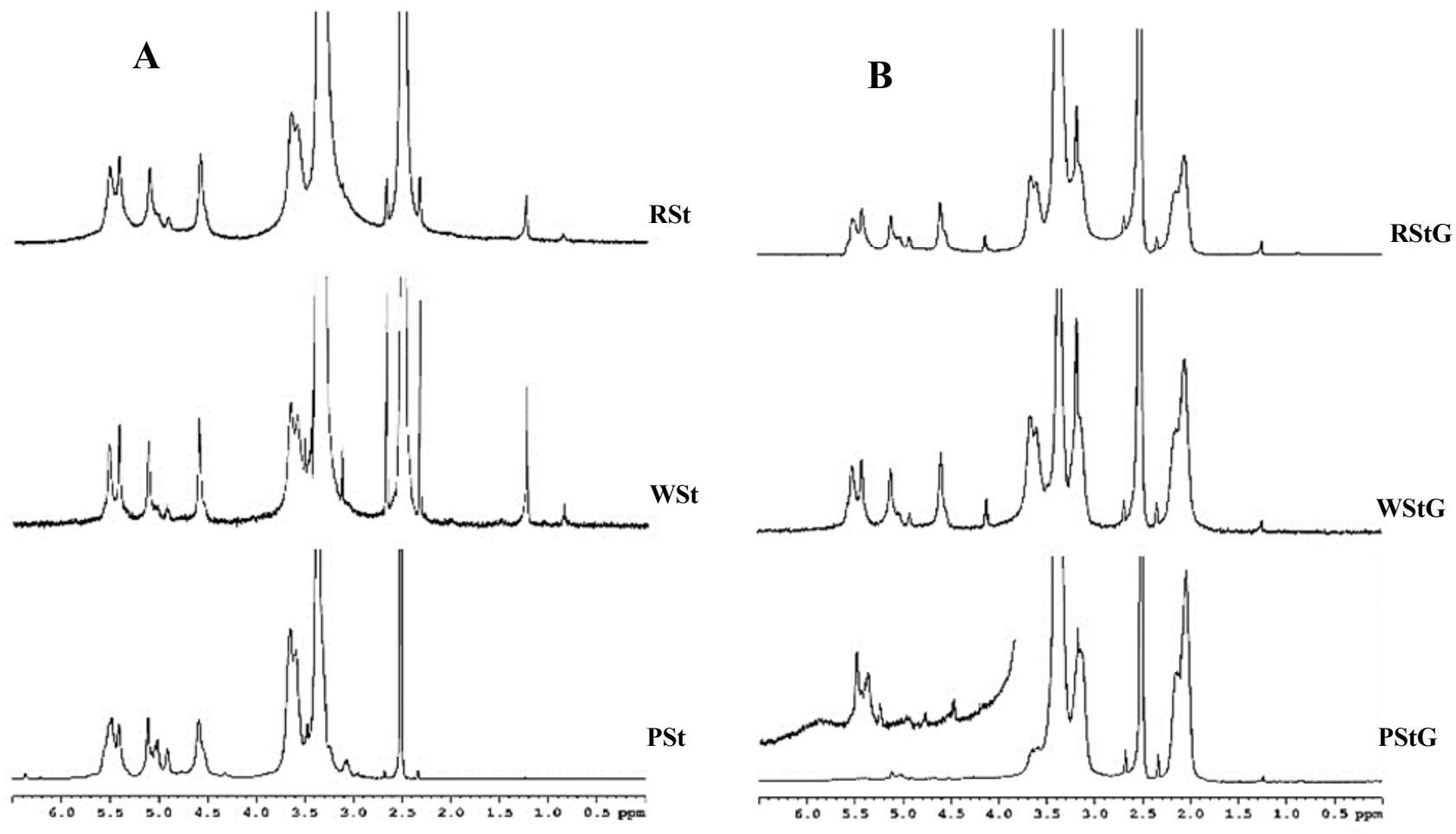

Fig. $3-{ }^{1} \mathrm{H}-\mathrm{RMN}$ spectra of (A) starch from potato (PSt), wheat (WSt) and rice (RSt) and (B) grafted copolymers (PStG, WStG, RStG). 


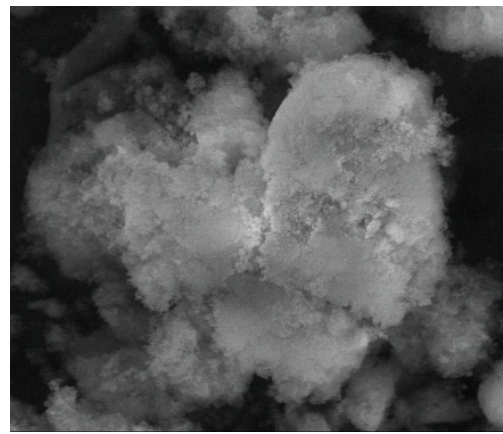

PStG

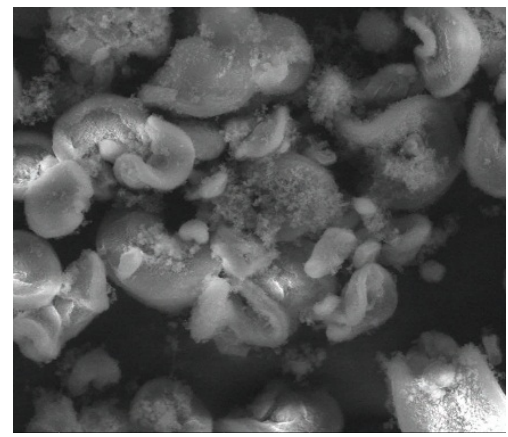

WStG

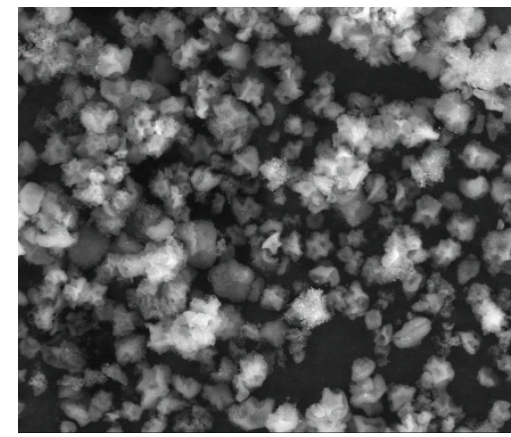

RStG

Fig. 4 - SEM images of grafted copolymers based on starch from potato (PStG), wheat (WStG) and rice (RStG); scale bar - $50 \mu \mathrm{m}$.

FT-IR spectroscopy offers clear information on the structure of the modified starch, after AN grafting (Fig. 2). FT-IR spectra of the grafted copolymers (coded PStG, WStG and RStG) contain the characteristic bands of starch, as follows: a broad band between $3600-3200 \mathrm{~cm}^{-1}$ assigned to the stretching vibration of $\mathrm{O}-\mathrm{H}$ bond, a band at $2932-$ $2939 \mathrm{~cm}^{-1}$ assigned to $\mathrm{C}-\mathrm{H}$ bonds and $-\mathrm{CH}_{2}$ groups, $\mathrm{a}$ band at $1636-1641 \mathrm{~cm}^{-1}$ assigned to the stretching of $-\mathrm{O}-\mathrm{H}$, and the bands located at about 1454, $1364-1371$ and $1248-1252 \mathrm{~cm}^{-1}$ assigned to the stretching of $-\mathrm{C}-\mathrm{H}$ bond and $-\mathrm{CH}_{2}$ and $-\mathrm{OH}$ groups, respectively. The characteristic bands of AGU ring are also present in the spectra of the grafted copolymer and can be observed at about 1155,1080 and $1022 \mathrm{~cm}^{-1}$, depending on the nature of starch. ${ }^{24,25}$ The high content of AN grafted on starch is supported by the intense band at $2245 \mathrm{~cm}^{-1}$ corresponding to the $-\mathrm{C} \equiv \mathrm{N}$ stretching.

The structure of grafted compounds was further confirmed by ${ }^{1}$ H-NMR spectroscopy (Fig. 3). The characteristic peaks of starch (Fig. 3A) were found at: $3.65 \mathrm{ppm}$, assigned to the protons of the carbon atoms in positions $\mathrm{C}_{2}, \mathrm{C}_{3}$ and $\mathrm{C}_{5} ; 4.58 \mathrm{ppm}$, assigned to the protons of the carbon atom in position $4 ; 5.1 \mathrm{ppm}$, assigned to the protons of the carbon atom at position $\mathrm{C}_{6}{ }^{26,27}$

${ }^{1} \mathrm{H}-\mathrm{NMR}$ spectra of the grafted copolymers (Fig. 3B) contain the characteristic peaks of both starch and $\mathrm{AN}$, confirming that the grafting reaction took place: peaks of AN at $2.0 \mathrm{ppm}$ (assigned to proton of the $\mathrm{CH}_{2}$ groups) and $3.1 \mathrm{ppm}$ (assigned to the protons of the $-\mathrm{CH}$ groups) and peaks of starch at $3.65 \mathrm{ppm}\left(\mathrm{C}_{2}, \mathrm{C}_{3}\right.$ and $\left.\mathrm{C}_{5}\right), 4.58 \mathrm{ppm}\left(\mathrm{C}_{4}\right)$ and $5.1 \mathrm{ppm}\left(\mathrm{C}_{6}\right)$.

Further evidence for the grafting selectivity of the used sorts of starch, the nitrogen percent was calculated from ${ }^{1} \mathrm{H}-\mathrm{NMR}$ spectra: $13.81 \%, 9.71 \%$ and $8.22 \%$ for PStG, WStG and RStG, respectively. The selectivity in grafting AN on the used starch samples can be ascribed to the differences in the content in amylose and amylopectin (Table 1), the high content of amylopectin branches in the crystaline domains and the location of amylose mainly in amorphous domains. Also, the fastest swelling capacity of potato starch will probably favor the access of AN to the grafting position, as compared to the other used starch samples.

The changes in the surface morphology of the grafted copolymers as compared to the starting starch granules (Fig. 1) were followed by SEM (Fig. 4). As Fig. 4 shows, the surface of native starch was partially modified, the morphology of the grafted copolymers being strongly influenced by the biological nature of used starch. Thus, after AN grafting on PSt (PStG) the granular structure of the PSt was completely modified, most probably due to the gelatinization, and amorphous particles of PStG can be observed, suggesting that the grafting reaction occurred in the starch amorphous region. When WStG and RStG were used, the SEM images of graft copolymers have clearly shown the deposit of polyAN on the particles surfaces, the morphology of the native starch grains keeping the initial shape after AN grafting.

The highest and fastest swelling capacity of potato starch (Table 1) would favor the access of AN to the grafting positions, as compared to the other used starch samples. Therefore, by fast swelling the gelatinization in PSt took place rapidly, activating the amorphous parts for grafting. By contrary, the slow swelling of WSt and RSt hindered the access of AN to the grafting position, the morphology of the native starch grains being preserved after AN grafting.

The quantitative elemental analysis results obtained by EDAX, are shown in Table 2, and confirm the grafting of AN onto starch by the nitrogen presence in the copolymer chemical composition. The content of AN on grafted copolymers depend on the type of starch, the highest $\mathrm{N} / \mathrm{C}$ ratio being recorded when potato starch was used and sustain the previously obtained results. 
Table 2

EDAX elemental analysis of starch from potato (PSt),

wheat (WSt) and rice (RSt) and of the grafted compounds (PStG, WStG and RStG)

\begin{tabular}{c|c|c|c|c|c}
\hline Elements/At. $\%$ & PSt & PStG & WSt & WStG & WSt \\
\hline C & 64.90 & 78.56 & 64.29 & 71.34 & 73.18 \\
O & 35.10 & 4.18 & 35.71 & 20.86 & 30.82 \\
N & - & 17.27 & - & 7.80 & - \\
\hline N/C & & 0.219 & & 0.109 & 9.08 \\
\hline
\end{tabular}

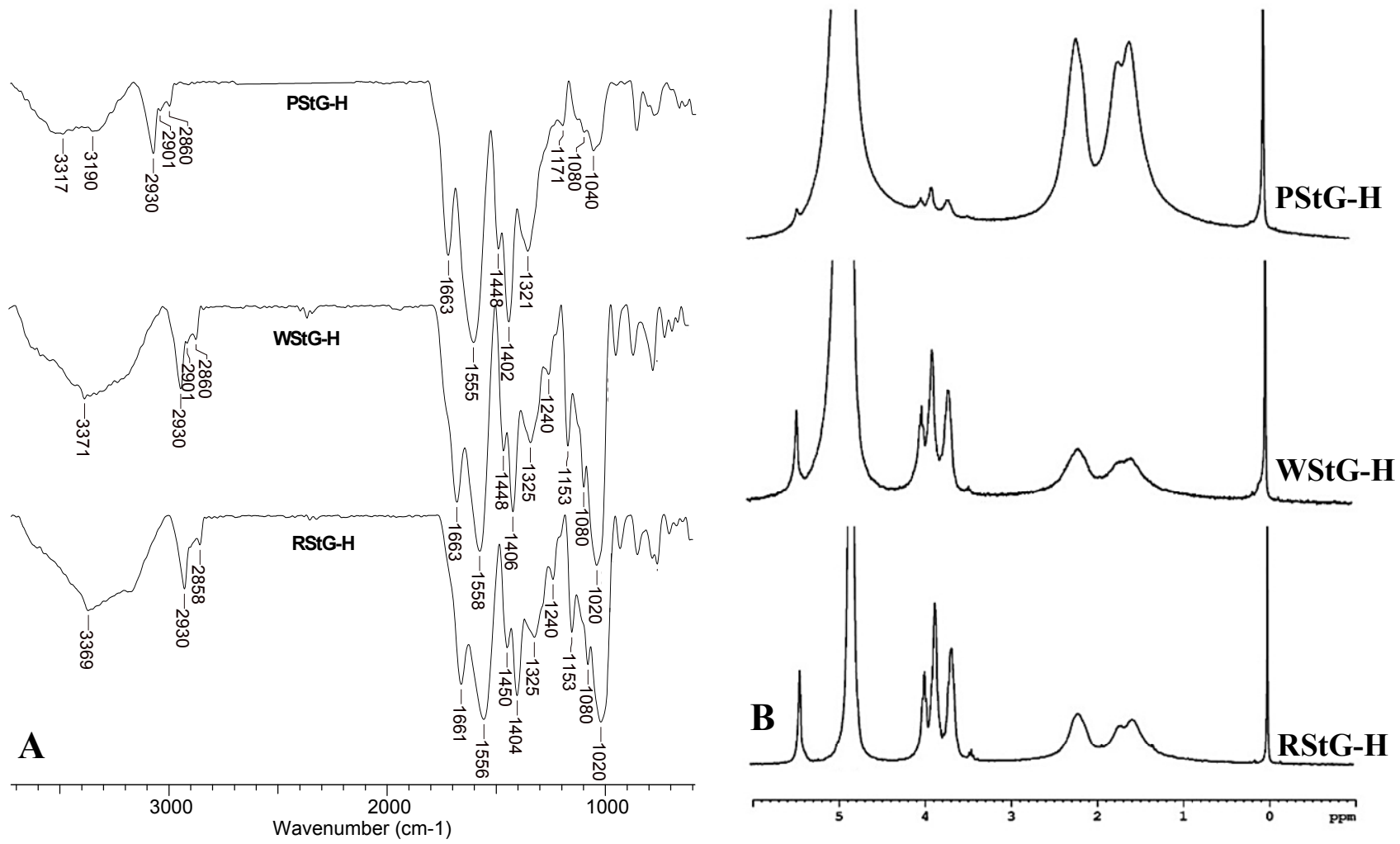

Fig. 5 - FT-IR (A) and ${ }^{1} \mathrm{H}-\mathrm{NMR}$ (B) spectra of the hydrolyzed compounds based on starch from potato (PStG-H), wheat (WStG-H) and rice (RStG-H).

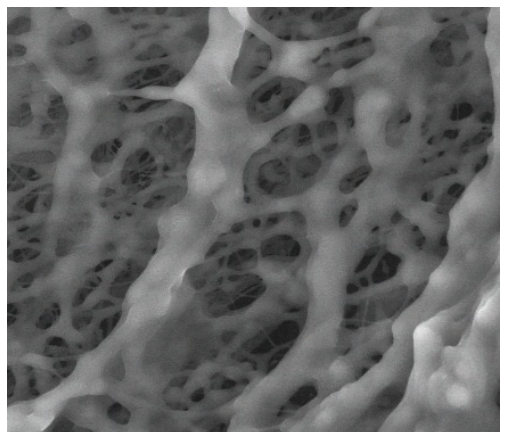

PStG-H

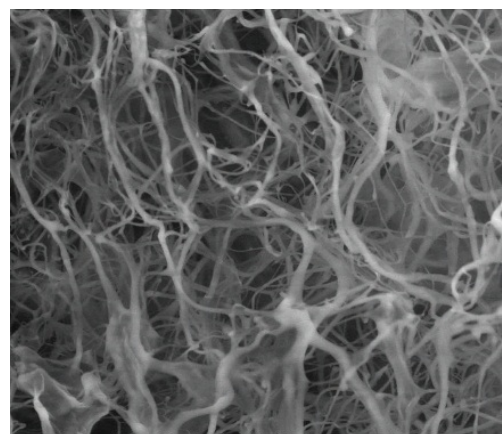

WStG-H

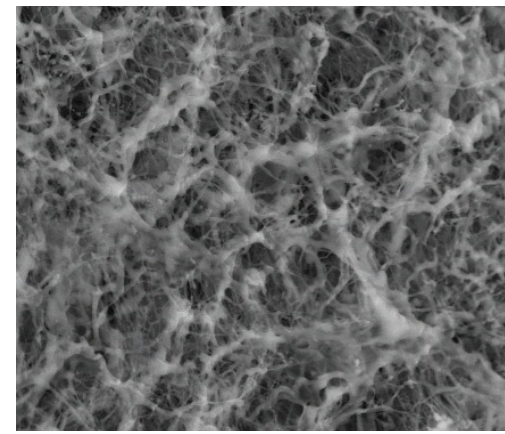

RStG-H

Fig. 6 - SEM images of the hydrolyzed compounds based on starch from potato (PStG-H), wheat (WStG-H) and rice (RStG-H); scale bar $-20 \mu \mathrm{m}$. 
Table 3

EDAX elemental analysis (atomic percentage) of the hydrolyzed compounds based on starch from potato (PStG-H), wheat (WStG-H) and rice (RStG-H)

\begin{tabular}{|c|c|c|c|} 
Sample Element & PStG_H & WStG_H & RStG_H \\
\hline $\mathbf{C}$ & 58.00 & 58.88 & 61.99 \\
\hline $\mathbf{O}$ & 29.47 & 32.94 & 31.17 \\
\hline $\mathbf{N}$ & 4.30 & 3.13 & 2.17 \\
\hline $\mathbf{N a}$ & 8.23 & 5.06 & 4.67 \\
\hline $\mathbf{N} / \mathbf{C}$ & 0.074 & 0.086 & 0.075 \\
\hline
\end{tabular}

Aiming to obtain water-soluble anionic polymers, the transformation of the nitrile groups to carboxylic acid groups was followed by the hydrolysis of the grafted products in the presence of $\mathrm{NaOH} .{ }^{19}$ Informations on the structure of the hydrolyzed copolymers (coded PStG-H, WStG-H and RStG-H) were obtained by the FT-IR (Fig. 5A) and ${ }^{1} \mathrm{H}-\mathrm{NMR}$ (Fig. 5B) spectroscopies.

In the FT-IR spectra of the hydrolyzed compounds (Fig. 5A), the characteristic band of nitrile group $\left(2245 \mathrm{~cm}^{-1}\right)$ is not visible, the presence of new bands being attributed to the functional groups generated by basic hydrolysis, as follow: $\sim 1663 \mathrm{~cm}^{-1}$ assigned to the stretching vibrations of the $\mathrm{C}=\mathrm{O}$ bond in amide group (amide I band); $1555-1558 \mathrm{~cm}^{-1}$ assigned to the vibration of $-\mathrm{COO}^{-}$ groups; $1448-1450 \mathrm{~cm}^{-1}$ assigned to the stretching vibration of $-\mathrm{CH}_{2} ; 1321-1325 \mathrm{~cm}^{-1}$ assigned to amide III. The bands at about 1153, 1080 and $1020 \mathrm{~cm}^{-1}$, characteristic of AGU units of the polysaccharide chain, are also visible after the hydrolysis reaction. Comparing the obtained spectra of the hydrolyzed compounds based on starch from potato (PStG-H), wheat (WStG-H) and rice (RStG$\mathrm{H})$, Fig. 5A revealed that the highest intensity of the band characteristic to the carboxylic group at $1556 \mathrm{~cm}^{-1}$ was obtained for PStG-H sample and suggest that hydrolysis percentage was the highest when potato starch was used.

The ${ }^{1} \mathrm{H}-\mathrm{NMR}$ spectra in Fig. 5B, shows some peaks of the hydrolyzed copolymers in the range of 3.7 to $4 \mathrm{ppm}$, assigned to the protons of the AGU unit, and peaks at $1.4 \mathrm{ppm}$ and $2.3 \mathrm{ppm}$ assigned to protons to sodium acrylate. The percent of sodium acrylate calculated from ${ }^{1} \mathrm{H}-\mathrm{NMR}$ was $39.54 \%$, $37.19 \%$ and $37.65 \%$ for PStG-H, WStG-H and RStG-H, respectively. These results can be also sustained by the results obtained by EDAX (Table 3). Also, from the ${ }^{1} \mathrm{H}-\mathrm{NMR}$ spectra we can conclude that the highest percentage of hydrolysis was obtained when potato starch was used, sustaining the FTIR results.
SEM images and EDAX analysis of the hydrolyzed compounds are summarized in Fig. 6 and Table 3. Thus, after the hydrolysis of the nitrile groups, the morphology of the hydrolyzed compounds appears like a "web spider" with different thickness of fibers and different sizes of pores, as a function of the starch native source.

The changes in the compounds morphology can be attributed to the formation of $-\mathrm{COO}^{-}$groups after the hydrolysis reaction. The differences in the SEM images can be correlated to the amyloseamylopectin ratio, which depends on the source of starch. The "web spider" like morphology, with interconnecting pores, which was evident after the drying of the gels by lyophilization, is also dependent on the hydrophilicity of the hydrolyzed samples, a higher swelling being found for the PStG-H than for the WStG-H, and RStG-H, due to the lower content in amylopectin of PSt, i.e. the less hydrophilic constituent of starch.

The elemental composition of the hydrolyzed compounds based on starch from potato (PStG-H), wheat (WStG-H) and rice (RStG-H) (Table 3) changed drastically as compared to that of grafted compounds (PStG, WStG, RStG) (Table 2). The decrease of nitrogen content in the hydrolyzed compounds is evident in EDAX results, mainly by the decrease of $\mathrm{N} / \mathrm{C}$ ratio, confirming that hydrolysis had occurred.

\section{EXPERIMENTAL}

Starch samples (PSt, WSt, and RSt) from Sigma-Aldrich were used as received. AN was distilled at about $77^{\circ} \mathrm{C}$ and kept at low temperature. $\mathrm{Ce}\left(\mathrm{SO}_{4}\right)_{2}$ reagent grade from SigmaAldrich and $\mathrm{H}_{2} \mathrm{SO}_{4}, \mathrm{NaOH}$ and methanol p.a., from Chemical Company, were used as received.

The grafting reaction was carried out in a two necked round-bottom flask equipped with stirrer and condenser. First, starch was gelatinized by heating its dispersion in water up to $80{ }^{\circ} \mathrm{C}$, about $30 \mathrm{~min}$, then cooling at $27{ }^{\circ} \mathrm{C}$. Then, an appropriate volume of $\mathrm{AN}\left(0.987 \mathrm{~mol} \mathrm{~L}^{-1}\right)$ and a calculated volume of $\mathrm{Ce}\left(\mathrm{SO}_{4}\right)_{2}$ solution $\left(2.6 \mathrm{~mol} \mathrm{~L}^{-1} \times 10^{3}\right)$ were added, under stirring, and the reaction took place for $1 \mathrm{~h}$. To separate the grafted and nongrafted fractions of starch, methanol has 
been used as nonsolvent, being added three times to the reaction mixture, followed by stirring and filtration. After filtration, the precipitate has been dried at $40{ }^{\circ} \mathrm{C}$, for $48 \mathrm{~h}$.

The hydrolysis reaction of the nitrile groups from grafted copolymers was performed as follows: $1 \mathrm{~g}$ of grafted copolymer and $15 \mathrm{~mL}$ of $\mathrm{NaOH} 2.5 \mathrm{M}$ were heated at $98^{\circ} \mathrm{C}$, for $6 \mathrm{~h}$. After hydrolysis, a homogeneous solution was obtained. To completely remove the hydrolysis agent, purification by dialysis of the hydrolyzed sample was performed until a neutral $\mathrm{pH}$ (about $72 \mathrm{~h}$ ). The water soluble polymer was recovered by freeze-drying.

FTIR spectra were recorded with a Bruker Vertex FT-IR spectrometer, resolution $2 \mathrm{~cm}^{-1}$, in the range of $4000-400$ $\mathrm{cm}^{-1}$ using the $\mathrm{KBr}$ disk technique. ${ }^{1} \mathrm{H}-\mathrm{NMR}$ spectra were recorded on ${ }^{1} \mathrm{H}-\mathrm{NMR}$ Bruker NEO-1 $400 \mathrm{MHZ}$. The surface morphology was investigated with an Environmental Scanning Electron Microscope (ESEM) type Quanta 200, operating at $20 \mathrm{kV}$ with secondary electrons, in low vacuum mode. For the determination of the elemental composition, the ESEM was coupled with an energy dispersive X-ray module (EDAX).

\section{CONCLUSIONS}

The paper follows the chemical modification of different sorts of starch (PSt, WSt and RSt) after grafting and hydrolysis reactions. The obtained products were deeply investigated by FT-IR and ${ }^{1}$ H-NMR spectroscopies, SEM and EDAX. FTIR and ${ }^{1} \mathrm{H}-\mathrm{NMR}$ spectra of grafted copolymers show the characteristic bands of both starch and AN, confirming that the grafting reaction took place. The surface of native starch was partially modified after grafting, the morphology being strongly influenced by the biological nature of used starch, the grafting reaction occurring mainly in the starch amorphous region. By the hydrolysis of grafted copolymers, water soluble polyanions were obtained. After hydrolysis, the morphology appears like a "web spider" with different thickness of fibers and different sizes of pore, as a function of starch source. FT-IR, ${ }^{1} \mathrm{H}-\mathrm{NMR}$ and EDAX shows that the highest percentage of AN grafting and hydrolysis was obtained when potato starch was used, as compared to the results obtained for wheat and rice starches.

Acknowledgements: The financial support of this research by the Project CNCS-UEFISCDI by the project PN-III-P1-1.1PD-2016-1313, within PNCDI III.

\section{REFERENCES}

1. A. G. Cunha and A. Gandini, Cellulose, 2010, 17, $1045-1065$.

2. R. Xiao and M. W. Grinstaff, Prog. Polym. Sci., 2017, $74,78-116$.

3. M. Tizzotti, A. Charlot, E. Fleury, M. Stenzel and L. Bernard, Macromol. Rapid Commun., 2010, 31, 1751-1772.

4. G. Crini, Prog. Polym. Sci., 2005, 30, 38-70.

5. O. Garcia-Valdeza, P. Champagneb and M. F. Cunninghama, Prog. Polym. Sci., 2018, 76, 151-173.

6. E. S. Dragan and D. F. Apopei, Chem. Eng. J., 2011, 178, 252-263.

7. E. Ogunsona, E. Ojogbo and T. Mekonnen, Eur. Polym. $J$, 2018, 108, 570-581.

8. C. J. Knill and J. F. Kennedy, in "Polysaccharides. Structural Diversity and Functional Versatility", 1998, cap. 26, p. 605-625.

9. X. Hao, Q. Chang, L. Duan and Y. Zhang, Starch/Stärke, 2007, 59, 251-257.

10. Z. Zhu, M. Li and E. Jin, J. Appl. Polym. Sci., 2009, 112, 2822-2829.

11. X. Zheng, L. Cheng, Z. Gu, Y. Hong, Z. Li and C. Li, Int. J. Biol. Macromol., 2017, 96, 11-18.

12. A. Pourjavadi and M. J. Zohuriaan-Mehr, Starch/Stärke, 2002, 54, 482-488.

13. V. Singh, A. Tiwari, D. N. Tripathi and R. Sanghi, Biomacromolecules, 2005, 6, 453-456.

14. A. Pourjavadi and M. J. Zohuriaan-Mehr, Starch/Stärke, 2002, 54, 140-147.

15. G. F. Fanta, F. C. Felker and R. L. Shogren, Carbohydr. Polym., 2004, 56, 77-84.

16. A. Hashem, M. A. Afifi, E. A. Al-Alfy and A. Hebeish, Am. J. Appl. Sci., 2005, 2, 614-621.

17. D. F. Apopei, M. V. Dinu and E. S. Drăgan, Dig. J. Nanomater. Bios., 2012, 7, 707-716.

18. M. W. Meshram, V. V. Patil, S. T. Mhaske and B. N. Thorat, Carbohydr. Polym., 2009, 75, 71-78.

19. E. S. Dragan and D. F. Apopei, Int. J. Biolog. Macromol., 2018, 120, 1872-1883.

20. A. S. Hoffman, Adv. Drug Deliv. Rev., 2012, 64, 18-23.

21. D. F. Apopei, M. V. Dinu, A. Trochimczuk and E. S. Dragan, Ind. Eng. Chem. Res., 2012, 51, 10462-10471.

22. M. Schirmer, A. Hőchstötter, M. Jekle, E. Arendt and T. Becker, Food Hydrocoll., 2013, 32, 52-63.

23. J. H. Trivedi, K. Kali, N. K. Patel and H. C. Trivedi, Carbohydr. Polym., 2005, 60, 117-125.

24. R. Kizil, J. Irudayaraj and K. Seetharaman, J. Agric. Food. Chem., 2002, 50, 3912-3918.

25. F. J. Warren, M. J. Gidley and B. M. Flanagan, Carbohydr. Polym., 2016, 139, 35-42.

26. D. C. Dragunscki and A. Pawlicka, Mat. Res., 2001, 4, 77-81.

27. M. Barikani and M. Mohammadi, Carbody. Polym., 2007, 68, 773-780. 
